\title{
A CAMPANHA \#FORARICARDOTEIXEIRA NO TWITTER: \\ INTERAÇÕES SOCIAIS E DEBATE PÚBLICO A RESPEITO DO ESPORTE
}

\section{MS. DIEGO DE SOUSA MENDES}

Departamento de Ciências da Educação Física e Saúde,

Universidade Federal de São João Del Rei

(São João Del Rei - Minas Gerais - Brasil)

E-mail: diegomendes20@hotmail.com

\section{GRAD. ARTHUR FRANCO E SILVA}

Licenciatura em Educação Física, Departamento de Ciências da Educação Física e Saúde, Universidade Federal de São João Del Rei

(São João Del Rei - Minas Gerais - Brasil)

E-mail: arthur_efi@hotmail.com

\section{GRAD. CARLA MONTEIRO SOUZA}

Licenciatura em Educação Física, Departamento de Ciências da Educação Física e Saúde, Universidade Federal de São João Del Rei

(São João Del Rei - Minas Gerais - Brasil)

E-mail: carlamonteirosouza@hotmail.com

\section{GALDINO RODRIGUES DE SOUSA}

Licenciatura em Educação Física, Departamento de Ciências da Educação Física e Saúde, Universidade Federal de São João Del Rei

(São João Del Rei - Minas Gerais - Brasil)

E-mail: galdinorodrigues@yahoo.com.br

\section{GRAD. MOACIR COSTA DO PRADO}

Licenciatura em Educação Física, Departamento de Ciências da Educação Física e Saúde, Universidade Federal de São João Del Rei

(São João Del Rei - Minas Gerais - Brasil)

E-mail: prado_moacir@yahoo.com.br

\section{GRAD. RODRIGO AUGUSTO RESENDE MORAIS} Licenciatura em Educação Física, Departamento de Ciências da Educação

Física e Saúde, Universidade Federal de São João Del Rei

(São João Del Rei - Minas Gerais - Brasil)

E-mail: rodrigoefi@yahoo.com.br 


\section{TAÍSE GIAROLA BARBOSA}

Licenciatura em Educação Física, Departamento de Ciências da

Educação Física e Saúde, Universidade Federal de São João Del Rei

(São João Del Rei - Minas Gerais - Brasil)

E-mail: taisegiarola@gmail.com

\section{RESUMO}

Em 20 I I ganhou espaço na mídia um movimento que se iniciou no Twitter e que reivindicava a saída do então presidente da Confederação Brasileira de Futebol (CBF). O episódio demonstrava o poder que a mobilização popular assumia nas Redes Sociais. A partir dessa temática, realizamos uma pesquisa com o objetivo de investigar como são os debates públicos sobre fatos esportivos na Rede Social Twitter, a partir de um estudo de caso da campanha "Fora Ricardo Teixeira". Para tal, analisamos 725 postagens textuais do Twitter e acompanhamos a campanha por seis meses. Constatamos que, para protestar, os participantes debatem entre si, divulgam opiniões pessoais e informações da mídia que não são presentes nos meios televisivos, além de abordarem a temática esportiva de modo amplo e crítico.

PALAVRAS-CHAVE: Redes sociais; internet; estudo de caso; Educação Física.

\section{INTRODUÇÃO}

Um dos fenômenos mais marcantes da comunicação social atualmente se encontra na internet, nas chamadas redes sociais. Quem de nós não se lembra ou não ouviu falar de sites como Orkut, Twitter e atualmente o Facebook? Esses sites representam hoje uma das principais formas de comunicação e trocas de informações pelos usuários da internet, tendo impacto em distintas áreas sociais, como a educação.

Com a comunicação mediada pelo computador, a produção e difusão de informação não estão mais concentradas apenas nas empresas midiáticas, o que por si só já trouxe mudanças significativas na forma como lidamos com todo tipo de bens simbólicos. Além disso, para Recuero (20 I Oa), a internet permitiu ampliar sobremaneira a capacidade de conexão entre as pessoas, permitindo que redes sociais fossem criadas no espaço virtual, conforme conhecemos hoje.

Nesse contexto, o "assunto esportivo" tem evidenciado no Brasil o poder das transformações trazidas pelas redes sociais na sociedade contemporânea. Em meados de 20I0, no Twitter,' milhares de brasileiros se conectaram em prol de

I. O Twitter é um site de rede social da internet que permite aos seus usuários enviar e receber textos de até |40 caracteres (conhecidos como "tweets"). Ali é possível criar um "perfil" (uma conta com dados de identificação do participante), "seguir" e ser "seguido" por outros. Quando um participante segue algum outro usuário, ele tem acesso a tudo o que este escrever/divulgar no site, por meio de uma ferramenta chamada timeline (linha do tempo). Do mesmo modo, tudo o que é postado por um participante em sua própria timeline fica visível para seus seguidores. Seguir alguém significa acompanhar aquilo que ele publica e ser seguido significa que pessoas 
protestar contra o locutor esportivo Galvão Bueno. A frase "Cala Boca Galvão" chegou à referida rede social e alcançou o primeiro lugar numa lista que destaca os assuntos mais comentados do site (os Trending Topics, ou Tópicos do Momento, em português). Em seguida, o assunto virou destaque da mídia brasileira, chegando a ser capa da Revista Veja (edição 2 170, de 21/07/20 I0) e protagonista de algumas reportagens televisivas nas principais emissoras nacionais.

Mais recentemente, em julho de 201 I, após uma polêmica entrevista concedida a uma Revista, o então presidente da Confederação Brasileira de Futebol (CBF) e do Comitê Organizador Local da Copa do Mundo de 2014 (COL), Ricardo Teixeira (RT), tornava-se o foco de uma nova manifestação popular nas redes sociais. Jovens comunicadores, torcedores organizados e "twitteiros" comuns lançaram um site $^{2}$ na internet e também um espaço temático exclusivo no Twitter (chamado de hashtag ${ }^{3}$ ), com o objetivo de reivindicar a saída do presidente dessas instituições. Os episódios evidenciam o poder que a mobilização popular assume nas redes sociais no que se refere à divulgação de informações e outros bens. Muitas manifestações populares sempre estiveram distantes dos meios de comunicação de massa, controlados pelas pautas decididas verticalmente, segundo critérios mercadológicos, políticos e ideológicos. Atualmente, conforme aponta Jenkins (2009, p. 29), vivemos um momento em que "as velhas e as novas mídias colidem, onde mídia corporativa e mídia alternativa se cruzam, onde o poder do produtor de mídia e o poder do consumidor de mídia interagem de maneira imprevisível".

Diante desse cenário, é possível perceber que o debate público acerca do esporte passa a fazer parte das relações sociais que acontecem na internet, e, mais do que isso, encontra nesse aparato condições específicas para produzir e reproduzir valores, ações e compreensões sobre o fenômeno esportivo. As redes sociais, pelos casos expostos acima, têm demonstrado que são possíveis espaços de resistências e tensões sociais a fatos que envolvem o mundo esportivo (midiatizado). Concordamos com Braga (2006, p. 14) que "por saber que é afetada pela midiatização, a sociedade se organiza para enfrentar sua mídia e essa organização afeta o conteúdo das produções midiáticas e o modo como cada indivíduo o recebe".

estão interessadas naquilo que você publica ou repassa de outras fontes. Como o espaço para publicação de textos é pequeno, é comum que seus usuários façam chamadas para acessar uma matéria completa em outras redes sociais ou sites informativos. Além disso, é possível enviar mensagens especificamente a outros usuários adicionando o símbolo "@" seguida do nome ou apelido deste. Também é possível reenviar a toda a uma rede específica de seguidores uma mensagem por meio de um botão denominado "Retweet". Maiores informações no endereço eletrônico https://twitter.com/

2. foraricardoteixeira.com.br

3. Hashtag são as palavras com um \# (jogo da velha) antes delas. Elas servem para que um usuário possa encontrar e acompanhar pessoas com os mesmos interesses, funcionando como um fórum temático. Fonte: http://www. planetatwitter.com/2009/08/o-que-e-e-como-usar-hashtag.html. 
A partir dessas constatações, desenvolvemos uma pesquisa com o objetivo de investigar como se dão as interações sociais e os debates públicos sobre fatos esportivos na rede social Twitter, a partir de um estudo de caso da campanha "Fora Ricardo Teixeira". Nossas questões de investigação foram: Como são as interações sociais no fórum de discussão (hashtag) "\#foraricardoteixeira"? Quais estratégias e assuntos são mobilizados pelos participantes? Quais padrões, similitudes ou tensões podem ser observadas nas interações dessa campanha? Há análises críticas em relação ao esporte e/ou a mídia nas opiniões e mensagens expressas pelos participantes? Há impacto social decorrente dessas ações instituídas no debate público sobre fatos esportivos na internet? Há relevância nessas mobilizações das redes sociais que possam ser exploradas/refletidas em ações educativas a partir da Educação Física?

Esclarecemos que nosso intuito não é esgotar tais questionamentos ou as potenciais reflexões que delas podem emergir, mas, ao contrário, buscamos constatações preliminares que nos permitam avançar nesse território ainda pouco explorado nas produções da Educação Física.

A respeito da metodologia, destacamos que a pesquisa foi realizada a partir de um Estudo de Caso da hashtag do Twitter "\#foraricardoteixeira". ${ }^{4} \bigcirc$ estudo contou com análises qualitativas e quantitativas. A parte quantitativa foi efetivada por meio de tratamento estatístico descritivo de 725 tweets coletados durante nove dias sequenciais (coleta entre 18 e 26 de Outubro de 201 I). A forma para coletar esses dados se deu via um mecanismo de busca existente no próprio Twitter, onde foi inserido o termo-chave "\#foraricardoteixeira". Deste modo, foi possível acessar os tweets submetidos à hashtag referida. Já a análise qualitativa foi realizada por meio de observações assistemáticas com registros em diário de campo (Agosto a Dezembro de 201 I ) e Análise de Conteúdo (BARDIN, 1979) 5 dos tweets coletados.

A respeito da amostragem, vale ressaltar que foram selecionados tweets que atendiam aos seguintes critérios: a) ter sido publicado em português; b) não ser tweets repetidos c) possuir comentário pessoal ou links ${ }^{6}$ (constatamos que muitos tweets continham apenas a frase "Fora Ricardo Teixeira", gerados de maneira automática pelo site da campanha, estes foram desconsiderados); d) ter relação direta

4. Para quem não tem acesso ao Twitter, a hashtag referida pode ser visualizada pelo endereço http://www.foraricardoteixeira.com.br/. É importante lembrar que havia mais de uma hashtag associada ao movimento.

5. Optamos por realizar uma análise do tipo Temática, em que o conceito central para organização do material são os temas das mensagens. Deste modo, o material foi decomposto em partes chamadas unidades de registro, que se referiam ao tema principal de cada tweet, e, em seguida, agrupados em categorias que permitiram realizar inferências (premissas aceitas pelos pesquisadores advindas do campo e dos referenciais teóricos) aos resultados.

6. Links é a abreviatura da palavra hiperlinks ou hiperligações da internet, em português. O seu significado é "atalho", "caminho" ou "ligação". São, portanto, atalhos designados a elementos clicáveis, em forma de texto ou imagem, que levam a outras partes da internet ou a outros documentos e fontes que não aqueles que se está a acessar imediatamente. 
com a campanha (constatamos que, em poucos casos, haviam tweets sem qualquer associação com a campanha).

\section{EXCURSO SOBRE A CAMPANHA \#FORARICARDOTEIXEIRA}

○ caso analisado nesse estudo teve início após uma entrevista publicada pela Revista Piauí (julho de 20I I), em que Ricardo Teixeira (RT) se mostrou indiferente às acusações feitas contra ele. Por este motivo foi criado no dia 21/07/I I o site foraricardoteixeira.com.br e a hashtag \#foraricardoteixeira. Menos de 24 horas após o início da campanha já haviam 28. 109 postagens. ${ }^{7}$

A campanha pedia a saída de RT da dirigência da CBF e da chefia do COL. $\bigcirc$ movimento foi organizado e divulgado por meio da internet e se difundiu por redes sociais diferentes, com a participação de torcedores e jornalistas, ganhando espaço nos grandes meios de comunicação. $\bigcirc$ Twitter foi uma das redes sociais que ganhou notabilidade durante o movimento, por promover debates e troca de informações sobre as denúncias contra RT .

No dia 27/07/I I a hashtag entrou para os trending topics e virou notícia em sites como o Lance!Net e Portal Terra. Na sequência, o assunto foi subitamente retirado desses tópicos, sendo considerado pelos usuários do Twitter uma forma de censura.

\# \#oraricardoteixeira extrapolou o espaço virtual e foi para as praças, avenidas e estádios do Brasil. O MASP (Museu de Arte de São Paulo) foi um dos pontos de encontro dos manifestantes. No Rio de Janeiro, aconteceu o protesto intitulado "Marcha por uma Copa do Povo: Fora Ricardo Teixeira", no Largo do Machado. Em uma rodada do Campeonato Brasileiro de futebol de 201 I, em que ocorriam clássicos nacionais, torcedores se mobilizaram com faixas, bandeiras, entre outras formas, para demonstrar que aderiram ao movimento. Há de se destacar que as transmissões televisivas se esforçaram para não mostrar integralmente os protestos, embora alguns veículos tenham dado o devido espaço às manifestações. Por fim, no dia 12 de Março de 2012, RT renunciou aos cargos que ocupava.

\section{FUNDAMENTAÇÃO TEÓRICA}

\section{REDES SOCIAIS: ÍMPETO NARCÍSICO E RESPOSTA SOCIAL À MÍDIA}

Grande parte dos brasileiros hoje já ouviu falar ou mesmo é membro de ao menos uma rede social da internet, mas, afinal, o que são tais redes e como estão integradas à cultura contemporânea? Quais suas características sociais? Em nosso

7. http://blogforaricardoteixeira.wordpress.com/ 
estudo buscamos refletir sobre estas questões como forma de nos aproximarmos e compreendermos melhor tal realidade e a apropriação de fatos esportivos por essas redes, num contexto de enfrentamento/ressignificação da mídia tradicional.

Segundo Haythornthwaite e Wellman apud Recuero (20 I 0a, p. I5), "Quando uma rede de computadores conecta uma rede de pessoas e organizações é uma rede social." Essa definição nos permite pensar as redes sociais não apenas como um fenômeno tecnológico, mas algo que resulta da interação social mediada pelas tecnologias digitais e que, portanto, tem em cada nó dessa rede pessoas historicamente situadas. Seguindo esta definição, Recuero (20 I0a), explicita que as redes sociais são constituídas de atores sociais (pessoas, instituições, grupos organizados etc.) e suas conexões. Os atores, no entanto, não se referem necessariamente a indivíduos imediatamente reconhecidos na esfera virtual, mas a representações performáticas desses. No Twitter, por exemplo, cada participante é representado por um "perfil", que pode conter sua foto ou uma imagem ilustrativa e dados pessoais que podem ser perfeitamente iguais aos de sua identidade civil ou, ao contrário, pode ser ficcional, daí a noção de "atores". Já as conexões de uma rede social podem ser compreendidas como os caminhos ou elementos que promovem a interação nas redes.

Na base das interações sociais mediadas pelo computador está a necessidade de dar fluxo/vazão ao excesso de informações e estímulos presentes em nosso tempo ou, ainda, o imperativo de tornar público o mundo, incluindo-se aí o que outrora foi considerado do âmbito privado. Além disso, desponta como necessidade, em uma sociedade amplamente individualizada, a busca permanente por socialização, por pontos de contatos com grupos sociais.

O sociólogo polonês Zygmunt Bauman (2008), em sua obra "Vida para o Consumo", analisa as redes sociais dentro de um espectro mais amplo do que ele chama de "sociedade de consumidores". Para esse autor, o que caracterizaria tal sociedade, mais do que a necessidade incessante em consumir, é o fato de haver uma transformação dos consumidores em mercadoria. Num mundo farto em informações e massivo, a subjetividade humana deseja tornar o sujeito visível e, para tal, força os sujeitos-consumidores cada vez mais a figurar com características daquilo ao qual se chamou mercadoria. Colocam-se em prateleiras de destaques online, promovem automarketing, enfim, fazem tudo para obter o olhar alheio, tal qual um produto no mercado. Neste universo, as redes sociais passam a figurar também como confessionários eletrônicos em uma sociedade que transfigura a todos em mercadoria:

Os adolescentes equipados com confessionários eletrônicos portáteis são apenas aprendizes treinando e treinados na arte de viver numa sociedade confessional - uma sociedade notória por eliminar a fronteira que antes separava o privado e o público, por transformar 
o ato de expor publicamente o privado numa virtude e num dever públicos, e por afastar da comunicação pública qualquer coisa que resista a ser reduzida a confidências privadas (BAUMAN, 2008, p. 9-10).

Por outro lado, ou, paradoxalmente, a possibilidade de relacionamento em redes online não apenas despertou/suscitou um "neo-narcisismo" mercantil na esfera individual, mas potencializou na esfera pública o âmbito da circulação de informações de todas as espécies, desde as mais frívolas e incipientes até mobilizações populares, análises e discussões midiáticas em uma amplitude antes possibilitada (a depender de seus crivos e interesses) apenas pelas grandes corporações de comunicação.

A Teoria da Recepção de Barbeiro (2008) e Orozco ( 199 I ) já havia anunciado o fim da crença de que a mídia atua apenas como um agente coercitivo frente a receptores passivos. Há algum tempo esses autores apontam que as condições culturais atuam como filtros que permitem à sociedade a capacidade de análise e resistência aos efeitos midiáticos. Mais recentemente, Braga (2006) tem enfatizado que, além de receptores de mensagens midiáticas, a população se organiza e faz circular de maneira diferida e difusa tais mensagens, redirecionando-as de forma impregnada de sentidos sociais, processo que o autor denomina como sistema de interação social sobre a mídia ou sistema de resposta social.

Devemos então distinguir: o que a mídia veicula (que se caracteriza, na verdade, como um sistema de produção) e o que, tendo sido veiculado pela mídia, depois circula na sociedade [...] Nesse tipo de circulação que nos interessa é que vamos encontrar o que a sociedade faz com sua mídia: é, portanto, uma resposta. (BRAGA, 2006, p. 28-29)

Nessa esfera da circulação das mensagens da mídia, Braga (2006) afirma que há enorme potencial crítico, pois há nessas manifestações tensionamentos dos processos e produtos midiáticos ou trabalhos analíticos-interpretativos que geram percepções ampliadas sobre fatos cobertos pela mídia. Deste modo, as redes sociais se tornaram dispositivos que permitem a circulação de informações e análises sobre fatos sociais midiáticos de maneira ampla, e, por vezes, com grau considerável de autonomia e crítica.

\section{O ESPORTE E A MÍDIA: TELESPETÁCULO E FALAÇÃO ESPORTIVA}

O esporte, com o passar dos tempos, foi adquirindo características que permearam o contexto social de cada época de seu desenvolvimento. Desse modo, com o advento das tecnologias de informação, o fenômeno esportivo ganhou espaço nos meios de comunicação de maneira significativa. Bracht (2005, p. 109) escreve que "os meios de comunicação de massa hoje não podem ser considerados 
elementos externos à instituição esportiva, são parte integrante dela, assim como as ciências do esporte".

Para Betti ( 1998), esta simbiose entre esporte e mídia gerou uma "realidade textual autônoma", denominada esporte telespetáculo ou esporte da mídia. Segundo esse autor, ao estarem na mídia, os esportes ganham contornos próprios para que possam ser retransmitidos. No caso televisivo, por exemplo, em busca de maior alcance, diferentes modalidades sofreram mudanças, principalmente em suas regras, para se adaptarem melhor à grade de programação. Assim, o esporte se tornou mercadoria a ser consumida via mídia e principalmente negociada.

No Brasil, o futebol tornou-se o esporte telespetáculo por excelência, tema central de informações e discussões que geralmente não ultrapassam o jogo em si, com previsões acerca de contratos, discussões polêmicas sobre arbitragem, da vida pessoal dos atores do espetáculo. Isso não é muito diferente nos sites da internet que abordam o tema. Como produto midiático, o esporte é produzido e editado pela conveniência da empresa transmissora. Para Pires (2006), a televisão, por exemplo, enfatiza o local onde acontecem os principais movimentos dos atletas, mas não é capaz de captar tudo o que se passa no estádio no momento de um jogo. $\bigcirc$ diretor de imagem passa a fazer a função do nosso cérebro (pela TV), selecionando as imagens que serão transmitidas ao telespectador. Nessas imagens os comerciais ganham destaque e, mesmo de forma inconsciente, o telespectador fixa o produto anunciado, numa estratégia subliminar de persuasão publicitária.

Fora o espetáculo midiatizado, o esporte passa também a ser assunto de noticiários esportivos, onde impera uma lógica do entretenimento, produzida para torcedores e aficionados, com "agendas das etapas de campeonatos, copas, e dados corriqueiros (factuais), ou então mitificando personagens: técnicos, jogadores, árbitros, atletas etc." (MESSA, 2005, p. I).

Toda a visibilidade da mídia gera uma série de discursividades a respeito do universo dos esportes, seus cenários e atores, denominada por Eco (1984, p. 223) como uma falação esportiva, ou seja, "quando o esporte passa a ser, essencialmente, um discurso da e sobre a imprensa esportiva". A falação esportiva, portanto, ocorre tanto em programas especializados, que buscam a participação dos espectadores, como é acionada no cotidiano da população. "O jogo deixa de ser apenas uma atividade praticada por determinadas pessoas, mas passa a ser visto por meio de sua alteridade - surge a figura do outro, do espectador" (MARQUES, 2002. p. 4).

A falação esportiva, portanto, atribui a ideia aos seus espectadores e agentes de que é possível ser um participante, de alguma forma, do espetáculo esportivo. Assim, quem mais domina os efêmeros assuntos em pauta na mídia a respeito de troca de treinadores, conduta pessoal de jogadores, entre outros, torna-se o "grande 
conhecedor". A falação, assim, é a possibilidade de compreender tudo sem qualquer apropriação preliminar da coisa (MARQUES, 2002. p. 5).

A ideia de falação esportiva por algum tempo foi indicativo da forma como a cultura da mídia se impregna no tecido social, determinando muitas vezes aquilo que deve ser comentado pelo público espectador, apontando como os discursos da mídia são reproduzidos na sociedade. Ou, ainda, pode ser uma estratégia de retroalimentação dos meios de comunicação para o monitoramento dos índices de audiência, a partir de uma ilusória co-participação do público. Entretanto, ao propiciar o debate público acerca dos esportes, podem surgir no cerne desse movimento interpretações sobre o que é ou não noticiado, sobre a forma como o esporte é tratado pela mídia. Daí a relevância em não apenas observarmos o que a mídia faz com a sociedade, mas de analisarmos o que a sociedade tem feito com a mídia, o que pretendemos aqui realizar.

\section{DESCRIÇÃO E ANÁLISE DOS DADOS}

Os dados coletados no "\#foraricardoteixeira" indicam três formas preponderantes de publicações (TABELA I): i) Os tweets opinativos, em que os sujeitos expressavam seus protestos, críticas, questionamentos etc; ii) tweets de conversação, ou seja, de troca comunicacional direta envolvendo dois ou mais participantes e; iii) tweets informativos, que repassavam informações (geralmente por meio de links) presentes na grande mídia e/ou nas mídias alternativas. Pudemos constatar que o Twitter é uma ferramenta utilizada com menor frequência para conversações e mais para fins de manifestações individuais, por meio da expressão de opiniões e conteúdos.

Tabela I. Tipos de Publicações presentes no Twitter

\begin{tabular}{ccc}
\hline Tipos de Tweets & Quantidade & Percentual \\
\hline Opinativos & 308 & $42,5 \%$ \\
Conversação & 270 & $37,2 \%$ \\
Informativos & 147 & $20,3 \%$ \\
\hline
\end{tabular}

Os principais assuntos mobilizados nos tweets foram organizados nas seguintes categorias: a) Futebol/Resultado Esportivo - tweets atrelados ao universo do futebol e/ou com manifestações passionais referentes aos resultados esportivos de clubes de futebol, seleção brasileira e demais esportes; b) Análise da Mídia - o assunto principal é a forma como a mídia cobre, divulga ou deixa de divulgar fatos atrelados 
a RT à campanha iniciada no Twitter; c) Protestos contra RT/ CBF/ FIFA - expressa manifestações contrárias à RT e demais entidades com as quais tem vínculo, no caso, CBF e FIFA; d) Crise Ministerial - tweets a respeito da crise do Ministério dos Esportes de 201 I, ocasionada por denúncias de desvio de dinheiro público destinados a projetos ligados ao esporte educacional para fins ilícitos; e) Megaeventos Esportivos - publicações a respeito de problemas estruturais e políticos envolvendo a realização dos Megaeventos Esportivos no Brasil (Copa do Mundo de Futebol de 2014 e Jogos Olímpicos em 20 l6); f) Adesão e Força da Campanha - tweets que acompanhavam o desenvolvimento da campanha \#foraricardoteixeira e/ou instigavam a participação de novos membros; g) Censura no Twitter - publicações que apontavam falta de lisura da empresa Twitter em relação à divulgação da campanha após episódio de retirada do \#foraricardoteixeira dos Assuntos do Momento; h) Lei da Copa - Estes tweets poderiam, em princípio, ser associados tanto à categoria "Crise Ministerial", como em "Megaeventos Esportivos", porém, como todos estes ambivalentes tinham em comum o assunto Lei da Copa, optamos por mantê-los em uma categoria à parte.

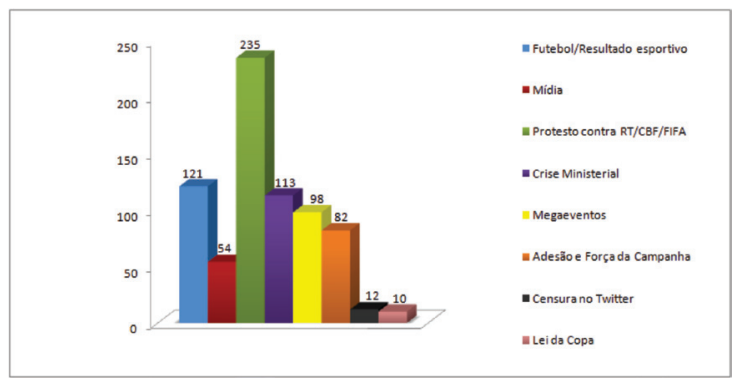

Gráfico I: Assuntos Mobilizados pelos participantes.

A maior parte dos participantes pareceu se envolver com a campanha especialmente para protestar de alguma maneira contra RT, CBF e/ou FIFA de um modo mais direto. Contudo, assuntos dos mais diversos foram associados ao protesto, como, por exemplo, a política esportiva nacional, visto que a categoria Crise Ministerial foi a terceira mais mobilizada, ou até mesmo a forma como a mídia cobriu ou deixou de cobrir denúncias e acontecimentos a respeito do ex-presidente da entidade máxima do futebol brasileiro. Se na sociedade atual o esporte é tratado apenas como espetáculo por parte dos meios de massa, na esfera pública parte da população (ainda que em pequena escala) parece se engajar em atividades interpretativas mais amplas, observando o esporte para além dos limites convencionais.

Quando cruzamos os dados dos tipos de publicações com os assuntos mobilizados pelos participantes, encontramos algumas tendências específicas. Entre os tweets opinativos, por exemplo, os assuntos mais mobilizados foram aqueles 
associados aos protestos diretos contra RT/CBF/FIFA è̀ categoria Futebol/Resultado Esportivo, conforme os exemplos abaixo:

$\underline{\text { Usuário Benedito }}^{8}$ : Já estamos cansado de tanta corrupção! \#CaiForaRicardoTeixeira vazaaa, \#ForaRicardoTeixeira: Já estamos cansado

Usuário Silva: O povo brasileiro precisa de 5 coisas: Saúde, Educação, Segurança, Emprego e... \#ForaRicardoTeixeira!

Usuário João: Temos que tira RT do poder! Melhorar o horario dos jogos a noite, e fazer um calendario digno de um futebol organizado. \#ForaRicardoTeixeira

Usuária Elena: CBF ameaça tirar jogo do Fogão x Flu do Engenhao para dar lugar ao lixo $x$ Vasco \#foraricardoteixeira

Usuário Gabriel: De fato o país do futebol não é mais do futebol. Perder de 3xI para a Costa Rica no Panamericano é brincadeira. \#ForaRicardoTeixeira

Os dois primeiros exemplos evidenciam aqueles protestos e opiniões que solicitavam a saída de RT da CBF, enquanto os três exemplos seguintes utilizavam o universo futebolístico e os resultados esportivos como artifício, corroborando com os estudos de Damatta (1985) a respeito do futebol como catalisador de debates públicos em nossa cultura. Estes últimos exemplos mostram as ambiguidades presentes nos esforços dos participantes, se para alguns, como o Usuário Benedito, a motivação de sua participação reside em uma reestruturação ampla do cenário do futebol, para outros a preocupação parece ser mais imediata, movida pela paixão por um determinado time ou ódio aos rivais. Constatamos, portanto, que, embora este ambiente virtual fosse destinado a um protesto específico, articulado a uma tradição corruptível da dirigência do futebol nacional, abordagens com menor potencial crítico se faziam presentes.

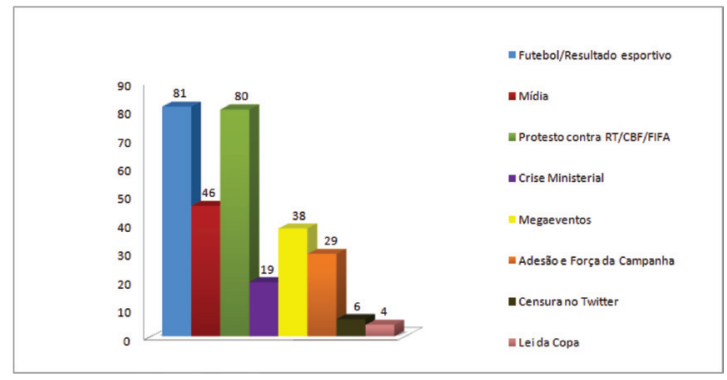

Gráfico 2: Assuntos Mobilizados nos tweets opinativos.

8. Os nomes dos atores foram substituídos para preservar suas identidades. 
Por outro lado, ainda entre os tweets opinativos, as análises a respeito da cobertura midiática sobre fatos que interligavam o esporte à RT tiveram uma grande frequência, conforme os exemplos abaixo:

Usuário Wilson: A imprensa deveria pedir o fim da ditadura na CBF \#ForaRicardoTeixeira

Usuário Leo: E a globo que não mostra os protestos nas torcidas, pq tem o ... preso com a cbf \#foraricardoteixeira

Usuário Ailton: Vexame: seleção bras. escalada pela \#Globo-CBF para boicotar a Record fracassa no \#Pan20 I I \#foraricardoteixeira

Neste ponto pudemos verificar que, paradoxalmente, o Twitter é ao mesmo tempo uma forma de mídia, um espaço invadido e retroalimentado pela mídia, mas também um canal de enfrentamento e interpretações dos meios de comunicação de massa. Segundo Braga (2006, p. 49-50), normalmente acreditamos que "uma posição crítica teria que se desenvolver em algum lugar extramidiático para, de algum modo totalmente externo e distante, examinar a mídia e apontar-lhe os descaminhos", sendo ofício para especialista. Contudo, sabemos que, ao ser exposta aos discursos e produtos da mídia, a sociedade coloca tais discursividades em movimento, os disseminam, conversam sobre esses assuntos e também os debatem e questionam, dependendo de suas condições culturais para realizar estas mediações (OROZCO, 1991), o que se reflete nas redes sociais.

Entre as análises da mídia, constatamos que a maior parte desses tweets direcionava suas críticas à empresa Rede Globo (embora outras também sejam citadas), e a principal constatação dos participantes era de que os meios de comunicação pouco divulgavam as denúncias correntes a respeito de RT e CBF ou, quando faziam, tratavam tais assuntos de modo tendencioso. Havia também entre os participantes associações especulativas diversas, como indica a postagem do Usuário Ailton, que apregoava o fracasso da seleção brasileira de futebol nos jogos Panamericanos de 20 I I a uma escalação tendenciosa da CBF, para prejudicar a audiência da empresa televisiva detentora dos direitos de transmissão dos jogos daquele ano, mas que não era a principal parceira política e econômica da entidade de RT.

Outra constatação foi que a mídia era o principal motor da campanha. As manifestações no Twitter ocorriam acompanhando os principais assuntos midiáticos do momento. Por exemplo, na semana em que a crise ministerial estava sendo amplamente divulgada pela mídia, este assunto foi o que mais movimentou as manifestações no Twitter. Durante os jogos Panamenricanos esse foi o assunto gerador das análises e manifestações. Isto nos mostra o impacto que os meios de comunicação exercem sobre nossa sociedade, pois, conforme Thompson ( 1995), 
a cultura é uma rede de sentidos e significados gerados, partilhados e ressignificados constantemente pela humanidade, e a mídia, nos tempos atuais, é a principal roda de fiar, tecendo incessantemente os fios dessa rede.

Entre os tweets de conversação, as manifestações e denúncias contra RT/ CBF/FIFA também foram o maior assunto de troca entre os participantes, mas em segundo e terceiro lugares aparecem as discussões sobre o andamento da campanha e a política esportiva nacional.

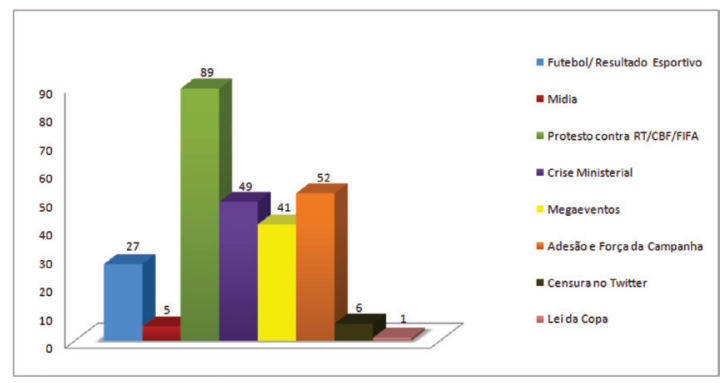

Gráfico 3: Assuntos Mobilizados nos tweets de conversação.

Percebemos que os participantes interagiram bastante na mobilização de novos membros e na autoavaliação da campanha, como demonstram os exemplos abaixo.

Usuário José: @usuário jefe Peça aos amigos e seguidores tuitarem e retuitarem \#foraricardoteixeira. É o grito do povo contra a corrupção

Usuário Soares: @usuário fredi Se cada uma tuitar \#foraricardoteixeira \#caiforaricardoteixeira 10 vezes por dia, destampa a cabeça do Ricardo Lixeira

Usuário Fredi: @usuário soares $\bigcirc$ \#foraricardoteixeira pode ter alguns dias fracos, mas ninguém pára mais o movimento.

Além disto, os participantes buscaram debater a política esportiva nacional, trocando informações sobre a crise no Ministério dos Esportes de 20 I I, que levou à queda do então Ministro. Na ocasião os participantes avaliavam as denúncias que saíam na mídia a respeito da crise, passaram a pressionar a saída do Ministro e discutir a respeito dos possíveis substitutos ao cargo.

Usuário Bruno: @joao \#foraricardoteixeira Era só o que faltava: depois de Agnelo e Orlando, Aldo Rebelo. Será que não tem alguém melhorzinho, Dilma?

Usuário João:@bruno Rebelo é farinha do mesmo saco e vai continuar a seguir os desmandos da FIFA. Quero Orlando Silva longe do ministério e \#foraricardoteixeira 
A discussão sobre política esportiva evidencia que parte da população que acompanha os esportes não se destina a uma falação centrada apenas no resultado esportivo, embora essa ainda seja uma tendência hegemônica. Os participantes da campanha Fora Ricardo Teixeira também se dedicam a discutir o esporte em um sentido mais amplo, acompanhando também o jogo político que perpassa o campo esportivo no país. Este fato nos leva a considerar as possibilidades de participação política presente na internet de modo geral, e nas redes sociais.

Para Gomes (2005), este tipo de intervenção social permite graus de participação no debate público que os meios de comunicação tradicional não atendem. Deste modo, o caráter democrático de tais práticas se deve a possibilidade de apresentar ao cidadão um estoque de informações relevantes, suficientes para habilitá-lo a identificar diferentes questões, argumentos, posições e matérias relativas aos negócios públicos e ao jogo político; além disso, permite o acesso a debates públicos já começados e possibilita iniciar novos debates, onde se pode exercitar a oportunidade de envolver-se em contraposições argumentativas, de desenvolver os seus próprios argumentos, de envolver-se em procedimentos deliberativos no interior dos quais pode formar a própria opinião e decisão políticas.

Segundo Gomes (2005), a internet tem sido um locus de participação política em nossa sociedade, embora com características específicas e diferenciadas do que se espera em uma democracia mais tradicional. Por exemplo, Gomes (2005, p. I3) destaca que

se torna acessível à esfera civil uma visão mais direta da sociedade política e das suas mensagens, dispensando-se, de algum modo, um sistema de intermediação considerado orquestrado, profissionalizado e que tenderia a tornar o público meramente apreciador do jogo político

Outro dado do estudo, as discussões sobre os Megaeventos ocupam a quarta posição nos assuntos mobilizados pelos participantes, seja nos tweets opinativos ou de conversaçãa. Esses tweets apresentavam um teor bastante crítico, no sentido de questionar intensamente a forma de organização desses jogos no país e os supostos legados que poderão ocorrer.

Usuário Neto: @Marcos600000 Será que os ladrões da Copa vão deixar algum dinheiro pros ladrões da Olimpíada? \#foraricardoteixeira

Usuário Jonas: Uma copa paga pelo povo para uma minoria rica que poderá pagar pelos caros ingressos. \#foraricardoteixeira

Por fim, os tweets menos comentados, mas também presentes nas conversas e opiniões dos participantes foram aqueles das categorias Censura no Twitter e Lei da 
Copa, ambos também não se restringem ao debate em torno do espetáculo esportivo. Os tweets a respeito da Lei da Copa carregavam características comuns aos debates em torno da Crise Ministerial, assumindo uma forma de participação no debate político esportivo, ao passo que os tweets a respeito da censura no Twitter apresentavam um tom de enfrentamento à mídia, conforme monstram os exemplos abaixo:

Usuário Tomás: A fifa esta mandando no país e vai aprovar a lei da Copa do jeito dela, a crise no ministerio facilita as coisas! \#foraricardoteixeira!

Usuário Lopes: O Twitter mente depois de tirar do ar "misteriosamente" a tag \#Fora RicardoTeixeira

Além de opinarem e conversarem sobre diferentes assuntos no Twitter a fim de provocarem manifestações contra RT e o universo do futebol brasileiro, diferentes notícias e reportagens midiáticas foram trazidas ao cenário das redes sociais como forma de reforçar ou apresentar novos argumentos ao debate, sendo as informações da mídia o principal "cimento" das interações sociais. Entre os veículos mais acessados estão o portal de notícias do UOL, seguido do portal Folha e do Estadão.

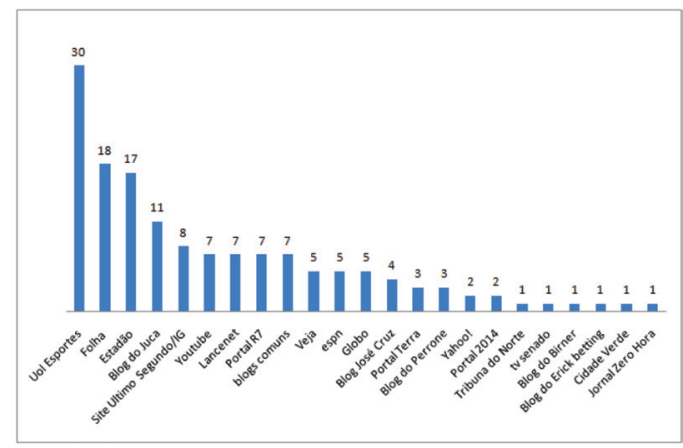

Gráfico 4: Veículos de Mídia utilizados como fonte de informações.

Segundo uma pesquisa realizada por Recuero (20 I0b), o Twitter tem um forte caráter informativo, sendo utilizado por seus usuários especialmente para repassar notícias e informações gerais por meio de links. Esta tendência também foi observada na hashtag estudada. A circulação de informação, contudo, tinha um caráter não apenas de manter informados os participantes, mas também de divulgar matérias que pouco se via nos meios televisivos. Não por acaso os principais veículos são onlines ou ligados aos jornais impressos, que normalmente são voltados a um público mais exigente quanto à qualidade das informações. 
Percebemos que as redes sociais com suas estruturas dotadas de fluxos multidirecionais de informação e comunicação, permitem aos participantes incrementar o poder simbólico e material das discussões sobre esporte, pois, ao expor suas convicções, posições e vontade a respeito de temas públicos, os participantes desses fóruns podem alterar as suas posições políticas para melhor ajustá-las à disposição do que foi motivado pelas interações dos participantes. Para Gomes (2005), isto pode produzir um efeito importante na cultura política, pois contribui para recompor a sensação de efetividade política da esfera civil e para produzir o sentimento de que os participantes são agentes políticos.

Se a Educação Física tem incorporado em suas práticas, pesquisas e reflexões sobre a forma como a mídia (re)trata os esportes e demais elementos da cultura corporal de movimento, a fim de exercer em suas ações educativas práticas de Mídia-Educação, é preciso que a área considere o que os jovens tem feito nas redes sociais. Afinal, estas novas mídias não apenas fazem parte de seus cotidianos de modo intenso, são também apropriadas de maneira crítica e criativa por parte da população.

The Campaign \#foraricardoteixeira on Twitter:

Social Interactions and Public Debate about Sport

ABSTRACT: In the year 201 I there was a lot of mentions in the media about a movement initiated in Twitter which claimed the president of the Brazilian Soccer Confederation (CBF). The episode showed the power that a popular mobilization is getting on the social network. From this thematic we did a research with the objective of investigating how the public discussions about sport facts are on the social network denominated Twitter, starting with a case study of the campaign "Out Ricardo Teixeira". We analyzed 725 text posts from Twitter and we spent 6 months monitoring the campaign. We are seeing that to protest, people involved keep discussions with others in the group, share personal opinions and information that are not available on the television. In addition, we have seen the sportive thematic being approached in a large and critical way. KEYWORDS: Social Networks; Internet; Case Study; Physical Education.

\section{La campaña \#foraricardoteixeira en el twitter: interacciones sociales y debate público a respeto del deporte}

RESUMEN: En 201 I tuvo espacio en los multimedios un movimiento que empezó en el Twitter y que reivindicaba la salida del presidente, a la época, de la Conferedação Brasileira de Futebol. El acontecimiento demostraba el poder que la movilización popular asumía en las Redes Sociales. A partir de esa temática realizamos una investigación con el objetivo de descubrir como son los debates públicos a respeto de acontecimientos deportivos en la 
Red Social Twitter, a partir de un estudio de la campaña "Fora Ricardo Teixeira". Para ello analizamos 725 postajes textuales del Twitter y acompañamos la campaña por seis meses. Constatamos que para hacer la protesta, los participantes debaten entre sí, divulgan puntos de vista personales y informaciones obtenidas a partir de los multimedios y que no son presentes en la media televisiva, además de abordaren la temática deportiva de modo amplio y crítico. PALABRAS CLAVE: Redes sociales; internet; estudio de caso; Educación Física.

\section{REFERÊNCIAS}

BARBEIRO, J. M. Dos meios às mediações: comunicação, cultura e hegemonia. 5. ed. Rio de Janeiro: Ed. da UFRJ, 2008.

BARDIN, L. Análise de conteúdo. Lisboa: Edições 70, 1979.

BAUMAN, Z. Vida para o consumo: a transformação das pessoas em mercadoria. Rio de Janeiro: Jorge Zahar, 2008.

BETTI, M. A janela de vidro: esporte, televisão e educação física. Campinas: Papirus, 1998.

BRACHT, V. Sociologia crítica do esporte: uma introdução. Vitória: Ed. da UFES/CEFED, 2005.

BRAGA, J. L. A sociedade enfrenta sua mídia: dispositivos sociais de crítica midiática. São Paulo: Paulus, 2006.

DAMATTA, R. Universo do futebol. Rio de Janeiro: Pinakoteca, 1985.

ECO, U. Viagem na irrealidade cotidiana. Rio de Janeiro: Nova Fronteira, 1984.

GOMES, W. Internet e participação política em sociedades democráticas. Revista da FAMECOS, Porto Alegre, v. 2, n. 27, p. 58-78, ago. 2005.

JENKINS, H. Cultura da Convergência. Rio de Janeiro: Aleph, 2009.

MARQUES, J. C. A falação esportiva: o discurso da imprensa esportiva e o aspecto mítico do futebol. In: XXV CONGRESSO BRASILEIRO DE CIÊNCIAS DA COMUNICAÇÃO, 25., 2002, Salvador. Anais Digital... Salvador: INTERCON, 2002. Disponível em: < http://www.intercom.org.br/papers/nacionais/2002/Congresso2002_Anais/2002_NPI8MARQUES.pdf >. Acesso em: 8 out. $201 \mathrm{l}$.

MESSA, F. C. Jornalismo esportivo não é só entretenimento. In: FÓRUM NACIONAL DE PROFESSORES DE JORNALISMO, 8., 2005, Maceió. Anais... Maceió: Fnpj, 2005. p. I-8. Disponível em: <http://www.fnpj.org.br/dados/grupos/jornalismo-esportivo-nao-e-so-entretenimento\%5B 169\%5D.pdf > . Acesso em: I0 nov. 201 I.

OROZCO, G. La audiencia frente a la pantalla: una exploración del proceso de redepción televisiva. Dialogos de la Comunicación, n. 30. p. 54-63, jun. 1991. Disponível em: < http:// perio.unlp.edu.ar/comunicacionyrecepcion/docs/Orozco\%20Gomez\%20-\%20La\%20 audiencia\%20frente\%20a\%20la\%20pantalla.pdf>. Acesso em: I 8 set. 201 | 
PIAUÍ. São Paulo: Ed. Alvinegra, edição 58, jul. 201 । .

PIRES, G. L. Esporte, mídia e ilusão. In: MELO, V. A.; TAVARES, C. (Org.). O exercício reflexivo do movimento: Educação Física, lazer e inclusão social. Rio de Janeiro: Shape; SESC, 2006.

RECUERO, R. Redes sociais na internet. Porto Alegre: Sulina, 20 I Oa.

RECUERO, R. "RT, por favor": considerações sobre a difusão de informações no Twitter. Revista Fronteiras: estudos midiáticos, São Leopoldo, v. I2. n 2, p. 69-8I, maio/ago. $2010 \mathrm{~b}$

THOMPSON, J. B. Ideologia e cultura moderna: teoria social crítica. na era dos meios de comunicação de massa. Rio de Janeiro: Vozes, 1995.

VEJA. São Paulo: Editora Abril, n. 2170, jul. 2010.

Recebido em: 15 maio 2012

Aprovado em: 04 out. 2012

Endereço para correspondência:

Diego de Sousa Mendes

Universidade Federal de São João del-Rei Campus Tancredo Neves (CTAN) - DCEFS - Sala I . I 5 EF Endereço: Avenida Visconde do Rio Preto, s/n,

Bairro Colônia do Bengo

São João del Rei (MG)

CEP 3630I-360 